\title{
GCU
}

Glasgow Caledonian

University

University for the Common Good

\section{A study of Turnitin as an educational tool in student dissertations}

Biggam, John; McCann, Margaret

Published in:

Interactive Technology and Smart Education

DOI:

$10.1108 / 17415651011031644$

Publication date:

2010

Document Version

Author accepted manuscript

Link to publication in ResearchOnline

Citation for published version (Harvard):

Biggam, J \& McCann, M 2010, 'A study of Turnitin as an educational tool in student dissertations', Interactive Technology and Smart Education, vol. 7, no. 1, pp. 44-54. https://doi.org/10.1108/17415651011031644

\section{General rights}

Copyright and moral rights for the publications made accessible in the public portal are retained by the authors and/or other copyright owners and it is a condition of accessing publications that users recognise and abide by the legal requirements associated with these rights.

Take down policy

If you believe that this document breaches copyright please view our takedown policy at https://edshare.gcu.ac.uk/id/eprint/5179 for details of how to contact us. 


\title{
A study of Turnitin as an educational tool in student dissertations
}

\author{
Dr John Biggam and Ms Margaret McCann \\ Department of Strategy and Innovation, Glasgow Caledonian University, Glasgow, \\ SCOTLAND
}

\begin{abstract}
Purpose - This paper explores the use of Turnitin as a learning tool (particularly in relation to citing sources and paraphrasing) and as a vehicle for reducing incidences of plagiarism.

Design/Methodology/Approach - The research was implemented using a case study of 49 final year "honours" undergraduate students undertaking their year-long core dissertation module. Over the course of the academic year student submissions to Turnitin were analysed in terms of improvements to their Turnitin scores and academic writing.

Findings - The majority of students submitted the first three chapters of their dissertation to Turnitin (Introduction, Literature Review and Methodology); less than half the students submitted their Findings and Conclusion to Turnitin. Over the course of the academic year, students submitted their dissertation work on average 5 times. Student Turnitin "similarity scores" were reduced but student use of Turnitin did not significantly enhance the quality of their writing.

Research Limitations/Implications - It is clear that mechanisms need to be explored to convince students of the potential educational benefits of Turnitin and to encourage staff to engage more in the process.

Practical Implications - Theoretically, using Turnitin for the dual purpose of preventing plagiarism and enhancing student academic writing skills has an obvious appeal; however, this study illustrates that one cannot take for granted both student and staff buy-in.
\end{abstract}

Originality/value - This paper is of value to academic staff who wish to explore the benefits, and pitfalls, of using Turnitin as an educational tool.

Keyword - Turnitin, Dissertations, Plagiarism, Educational Tool, Writing Skills.

Paper Type - Case Study

\section{Introduction: Rationale for Using Turnitin}

Plagiarism is a growing problem in Universities (Park, 2003; Peacock et al., 2006; Biggam, 2008). Furthermore, the reasons for plagiarism are not hard to fathom. There is the deliberate cheat consciously intent on submitting work that is not their own. Then there is the student who does not know that what he is doing counts as plagiarism, or he does know but lacks the skills to do anything about it (or thinks that it is acceptable practice). The pressure of work may lead students to turn to plagiarism as a quick solution. Some students may look at the penalty for plagiarism and decide that it is not a deterrent and decide, furthermore, that cheating was a sensible use of their resources. Some even claim that the use of Turnitin, an anti-plagiarism tool in commonplace usage in Universities (Regan, 2008), has contributed to the increase of essay-bank sites as a result of a technological tit-for-tat war (Kantor, 2006).

Notwithstanding the aforementioned criticism of Turnitin, other detractors criticize the effectiveness of Turnitin in either detecting plagiarism or deterring acts of plagiarism (Hayes and Introna, 2005; Biggam, 2007; Davis, 2008). For example, Marshall and Garry (2006) raise the point that many students themselves appear unaware of what constitutes plagiarism. Biggam (2008) underlines this point when he identifies a variety of different types of plagiarism: wholesale unacknowledged copying of text verbatim, patchwork 
plagiarism, poor paraphrasing, and taking someone else's ideas without due acknowledgement.

However, the purpose of this paper is not to delve into the causes of plagiarism or to work out how to punish transgressors. This study aimed to implement part of the holistic model developed by Biggam (2008) on dealing with plagiarism: the education of students to minimize incidences of plagiarism. The authors wanted to find out if students would use Turnitin voluntarily to understand the different types of plagiarism that can occur in their own work, to improve their writing skills, and to, in the end, reduce the chances of plagiarism in their final submission. The findings of this paper, based on empirical research ought to help those institutions interested in using Turnitin as a learning tool to confront plagiarism. The next section outlines the selected case study and how Turnitin was set up for the students.

\section{Case Study Set-up: Dissertation Module}

This empirical research focused on final-year "honours" undergraduate students undertaking their core dissertation module in the business school of a University in Scotland. Why select these students for the study of Turnitin as a learning tool? The honours dissertation is a substantial piece of independent academic research writing which students conduct on a topic related to their programme of study, and draws on knowledge gained throughout their degree. Students select their dissertation topic in September, at the start of the academic year, and submit their completed dissertation at the end of April, towards the end of the academic year. Students must demonstrate wide reading and critical understanding of established theories, principles and concepts, as well as develop and conduct research appropriate to their research objectives. This means that students are required, inter alia, to be competent at citing sources. The module is assessed solely on submission of the 10,000 word dissertation. In this study, 49 students submitted a final dissertation.

Another reason for using Turnitin is that depending on supervisors to 'manually' detect plagiarism can be unreliable and that, as a result, the cases detected in previous years may be the tip of the iceberg. Furthermore, when a student is suspected of plagiarism, it can take a great deal of staff time and effort trying to identify and collate evidence. Typically, staff entered suspected text from a student's dissertation into Google and if the resulting search was productive (as shown in Figure 1) then further searches were initiated.

Figure 1. Using Google to Detect Plagiarism

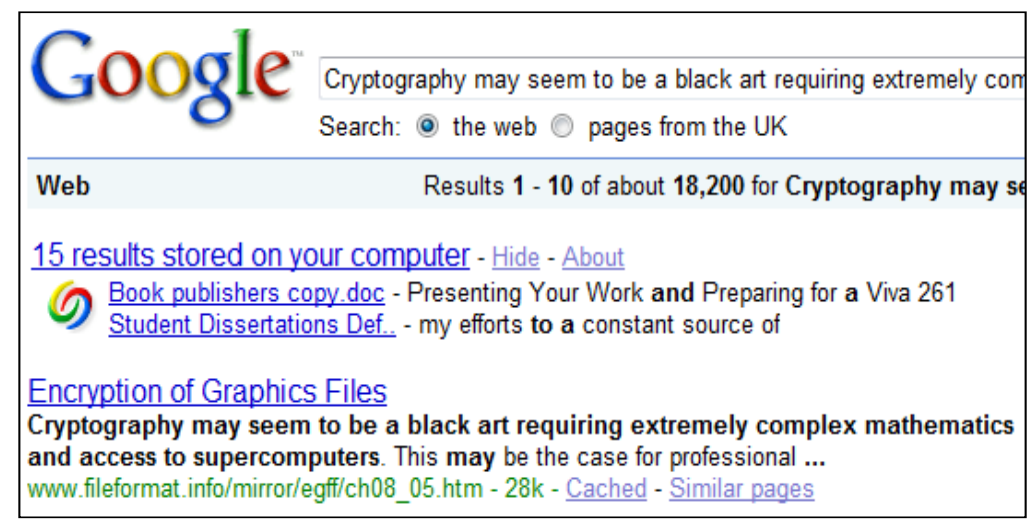


However, if a student used many unacknowledged sources in their work (even within one page of their dissertation), then the effort needed to find evidence of plagiarism was extremely onerous and time-consuming, to such an extent that it would not be surprising if some staff preferred not to look for plagiarism in a student's dissertation. It was therefore decided to implement the use of Turnitin within the dissertation module, both as a learning tool for students to prevent plagiarism and promote good practice during the writing stage and to minimize the workload on staff trying to detect plagiarism in a student's work and so, in the end, reduce the overall extent of plagiarism.

Turnitin is available through the University VLE, Blackboard, and has been set up in the following way. Within the dissertation module in Blackboard, students submit work for checking through the Assignments section. Since Turnitin only allows students to submit one piece of work per Assignment (without overwriting a previous submission), an 'assignment' has been set up for every dissertation chapter, named Chapters 1-6. This allows students to submit and check each chapter individually. It was anticipated that Chapter 1 would equate to the dissertation Introduction, Chapter 2 to the Literature Review, Chapter 3 to Research Methods, Chapter 4 to Empirical Findings, Chapter 5 to Conclusion, with Chapter 6 a spare chapter to be used at the student's discretion (perhaps for the Abstract). The module leader set up Turnitin so that students could also submit a complete draft of their dissertation prior to the compulsory submission of their final work into Turnitin. When a piece of work is submitted, a report is generated, usually within 1015 minutes of submitting the file, which can be read by both the student and their supervisor. If any assignment (i.e. chapter) is submitted twice, the previous version will be overwritten and a new report created but it may take up to 24 hours to generate the report for the resubmitted file.

During the draft writing stage, students can submit each chapter individually, gain relevant feedback reports, reflect on the results, and rewrite and resubmit as often as required. This can be done in conjunction with their supervisor. In addition to submitting each chapter, students are asked to submit their complete draft to Turnitin which will be used by their supervisors for feedback and comment before students complete their final work.

\section{Phase 1 of Study: Initial Findings}

In lectures prior to students starting their dissertation, they were advised of expected timescales for completion of the various parts of their dissertation: before Xmas they should, at the least, complete their Introductory chapter (chapter 1), their Literature Review (chapter 2) and, ideally, their chapter on Research Methods (chapter 3). However, the first student submission to Turnitin appeared on $4^{\text {th }}$ December 2008 , despite students working on their dissertation since September (theoretically, at least!) and by the beginning of March, of the students who submitted their work to Turnitin, only 15 of them had completed drafts of their first 3 chapters, a far cry from supervisor expectations. Table 1 shows the level of student submission activity up until $7^{7 \mathrm{~h}}$ March 2009:

Table 1. Student Submission Activity to $7^{\text {th }}$ March 2009

\begin{tabular}{|l|c|c|c|c|c|c|}
\hline Chapter & 1 & 2 & 3 & 4 & 5 & 6 \\
\hline No. of Students & 11 & 15 & 13 & 0 & 0 & 0 \\
\hline
\end{tabular}


So, only 15 of the 49 students submitted their Chapter 2 into Turnitin and 13 students submitted their Chapter 3. This lack of progress on their dissertations reflects anecdotal evidence from supervisors that students, in Semester A, tend to concentrate on other modules, and that it is in Semester B (after the Xmas break) when students decide to focus their attention on their dissertation.

Two points need to be made: firstly, despite email requests from the module leader reminding students to make use of Turnitin, the majority of the 49 dissertation students ignored her pleas (at that time only 20 students in total used Turnitin in one way or another); secondly, as of $7^{\text {th }}$ March, none of the submitting students appeared to have started, never mind completed, their empirical work and, worse, some students were still struggling with the Literature Review. If this was reflective of the general module population then students would toil to complete their dissertation or, even if they did, to do it justice.

Once again, this reflected staff anecdotal evidence of general student strategies for dissertation completion: leave it late then put in a concentrated effort. Perhaps this is how students prefer to work. It may be that this pattern of study generates a level of panic and causes some students to resort to plagiarism, in which case the module team may have to concentrate on teaching students about dissertation strategies and the consequences of their chosen approach.

Figure 2. Student Turnitin Extract

\begin{tabular}{|c|c|c|c|c|}
\hline Similarity: $22 \% \square \quad$ exclude quoted exclude bibliography & & & & mode: show highest matches together. \\
\hline \multirow{3}{*}{\multicolumn{2}{|c|}{$\begin{array}{l}\text { are held accountable for promoting and protecting the } \\
\text { environmental, health, and safety regulations of } \\
\text { workers that make their products, regardless if they are } \\
\text { direct employees or work for their suppliers. For example, } \\
\text { companies like Nike, Disney, and Wal-Mart have faced } \\
\text { damaging media reports, external pressure from activists, } \\
\text { and internal pressure from investors demanding that } \\
\text { companies acknowledge responsibility for labour rights } \\
\text { abuses in factories that make their productsArriaga, } 2008 \\
\text { Arriaga, }\end{array}$}} & & 1 & $\begin{array}{l}12 \% \text { match (publications) } \\
\text { Cruz, J.M... "Multiperiod effects of corporat } \\
\text { social responsibility on supply chain } \\
\text { networks, transaction costs, emissions, an } \\
\text { risk", International Journal of Production } \\
\text { Economics, 200811 }\end{array}$ \\
\hline & & & 2 & $\begin{array}{l}\text { 3\% match (Internet from 22/05/08) } \\
\text { http://www.csrresults.com }\end{array}$ \\
\hline & & & 3 & $\begin{array}{l}\text { 3\% match (Internet from 30/04/08) } \\
\text { http://www.oww-consulting.com }\end{array}$ \\
\hline $\begin{array}{l}\text { A., 2008. Business and human rights. Amnesty } \\
\text { International USA. Available from: } \\
\text { http://www.amnestyusa.org/business/csr.html.. }\end{array}$ & 1 & & 4 & $\begin{array}{l}1 \% \text { match (Internet from } 11 / 08 / 08 \text { ) } \\
\text { http://pmac.ca }\end{array}$ \\
\hline \multirow{2}{*}{$\begin{array}{l}\text { McDonalds, Mitsubishi, Nestle, Nike and Shell, have also } \\
\text { suffered damage to their reputations and sales as a } \\
\text { result of public awareness campaigns by advocacy groups } \\
\text { about their CSR practices. Svendsen et al., (2001). }\end{array}$} & 1 & & 0 & http://www. bentley.edu \\
\hline & & & 6 & $\begin{array}{l}1 \% \text { match (publications) } \\
\text { Marketing Intelligence \& Planning, Volume } \\
\underline{25, \text { Issue } 1(2007-02-04)}\end{array}$ \\
\hline
\end{tabular}

Turnitin colour-codes the suspected level of plagiarism (or "similarity matching" to be more accurate) as follows: Blue (no matching words); Green (up to 24\% similarity); Yellow (25-49\% similarity); Orange (50-74\% similarity); and Red (75-100\% similarity). The level of "similarity" - an interesting euphemism used by Turnitin - was such that at $7^{\text {th }}$ March 2009: 7 students were on or under 3\%; 2 students at 10\% and 9\%; with another two at $16 \%$ and $22 \%$. Some of the "similarity" will occur because the students may have similar structures (set by University guidelines) and similar headings ("Chapter 1", "Introduction", etc.) with similar set text (Departmental title, University name, etc.). At a glance students could get some sort of idea of where they stood in terms of University 
regulations. Equally important, staff could see which students might need help in understanding how to reduce their level of plagiarism. Only by looking at the detail of the submissions, could staff see in what areas students needed help. For example, the following extract (Figure 2) shows that this student engaged in straight-forward cut-andpaste copying of someone else's work and that he needed advice on how to, at least, make use of quotations and to credit the source. It was seen as important not to use this evidence to admonish students as this would defeat the purpose of using Turnitin as a learning tool.

There was a great deal of evidence showing that students needed to be (re-)taught how to avoid blatant copying and patchwork plagiarism. Perhaps the earlier lessons given at the start of the module on plagiarism were seen as abstract issues to the students because they had not yet started their dissertations at the time. This time the tuition may be more pertinent because it would be based with reference to the student's own work. What was interesting about the patchwork plagiarism was the choice of "filler" words that students used, very often reflecting a poor standard of English or, more likely, direct use of a thesaurus without checking to see if the substitute words made sense. Figure 3 is a typical example of patchwork plagiarism found in the submissions. In this example the word "disturbed" adds an alarming imagery to the sentence. The actual source text from which the student was trying to use, read: "The results suggest that, even when controlling for differences in Internet usage, women perceive a higher level of risk in online purchasing than do men" and is attributed to Garbarino and Strahilevitz (2004, p.768).

Figure 3. Example of Patchwork Plagiarism

in online buying is that women are more disturbed than men with the risk of purchase online

The Turnitin software was useful in the above example (and many like it) from a number of perspectives. First of all, it let the student's supervisor know in what way their student needed help. Secondly, by following the link to the actual source provided by Turnitin, the supervisor would notice that the student extracted the material from an abstract (to access the full paper required payment) and so it was clear that the student was gaining only surface knowledge on topic areas crucial to his dissertation. Lastly, the student could focus on the text that was picked up by Turnitin and query their supervisor on what was wrong with it or make an improved effort themselves. Another advantage of Turnitin was that supervisors could observe the poor level of referencing (separate from any type of plagiarism on show). For instance, some students would reference an author without any use of parenthesis - e.g. "Thomson 2007" instead of "(Thomson, 2007) or "Thomson (2007)...". Once again, supervisors could move quickly to help students remedy such errors.

Table 2 correlates the submission types (at this stage in the research, the students had completed three types of submission: Introduction, Literature Review and Research Methods) against Turnitin's similarity index (Blue: no matching words; Green: up to 24\%; etc.), where $\mathrm{S} 1=$ submission $1, \mathrm{~S} 2=$ submission 2 , and $\mathrm{S} 3=$ submission 3. 
Table 2. Chapter submission against level of similarity index

\begin{tabular}{|l|c|c|c|c|c|}
\hline & $\begin{array}{c}\text { Blue } \\
(=0 \text { similarity })\end{array}$ & $\begin{array}{c}\text { Green } \\
(<=24 \%)\end{array}$ & $\begin{array}{c}\text { Yellow } \\
(25-49 \%)\end{array}$ & $\begin{array}{c}\text { Orange } \\
(50-74 \%)\end{array}$ & $\begin{array}{c}\text { Red } \\
(75-100 \%)\end{array}$ \\
\hline Introduction & $2[\mathrm{~S} 1]$ & $8[\mathrm{~S} 1], 1[\mathrm{~S} 2]$ & - & - & - \\
\hline Literature Review & - & $12[\mathrm{~S} 1], 13[\mathrm{~S} 2], 3 \mathrm{~S}[3]$ & $1[\mathrm{~S} 2]$ & - & - \\
\hline Research Methods & $2[\mathrm{~S} 3]$ & $8[\mathrm{~S} 2]$ & - & - & - \\
\hline
\end{tabular}

No student submissions recorded a similarity score over $49 \%$ and 4 submissions obtained a similarity score of $0 \%$ (for Introduction and Research Methods). The 2 students who achieved no similarity match for their chapter on Research Methods, although commendable, nonetheless had a consistent low similarity score for their Introduction and Literature Review submissions (1\% and $4 \%$ for student 1 , and $4 \%$ and $3 \%$ for student 2 ), so it is not that the students were learning as a result of previous discretions (though it might be argued that the system of using Turnitin in the first place concentrated their minds). The bulk of submissions hit the green zone (up to $24 \%$ similarity match) as follows: 9 Introduction chapters, 28 Literature Reviews, and 2 Research Methods.

When analyzing the data, it very quickly became apparent that the colour-coded similarity groupings within Turnitin were too broad and that within each band the range of similarity matchings between students were wide and varied. For example, in submission 2 (theoretically Chapter 2 i.e. submission of the Literature Review), within the green zone (similarity match up to $24 \%$ ), some students were achieving a score of $3 \%$ while others were getting scores of $17 \%$ and $20 \%$. Supervisors could not depend purely on the colourcoding system in deciding if a student needed support. Students who managed to get low similarity scores may have felt that they merited a different colour-code from those whose scores were at the extreme end of the same band (an issue the research team will be investigating later). On the other hand (in relation to supervisor support) too keen a dependency on the colour-codes and matching scores may cause staff to assume that students with low similarity scores may not need help. For instance, a student with a $0 \%$ match in his Research Methods needed guidance, when one looked at what he had written, on structuring his chapter; similarly, another student with a 3\% score in his Literature Review required tutoring on the difference between "description" and "critical evaluation".

What of the type of "plagiarism" detected? Under the "Chapter 1" submission heading, the main type of suspected plagiarism involved a mix of blatant copying (the higher scores, and the majority) with patchwork plagiarism (the lower scores); under the "Chapter 2" submission, it was one again a mix of types between unadulterated copying and piecemeal plagiarism (this time the mix was more even); and under "Chapter 3", once again a mix between direct copying and patchwork copying (but with more concentration on patchwork plagiarism). Two other points to be made: where similarities were highlighted by Turnitin, students did not make an attempt to paraphrase an author's work but instead either copied verbatim or simply replaced some of the words with (what they thought) was a synonym; also, students need to learn to exclude quoted text when submitting to Turnitin (can skew similarity score, in some cases quite significantly).

Did the similarity of scores of individual students decrease over time, from when they submitted under Chapter 1 to the Chapter 3 submission? Table 3 is a record of student similarity scores, as they progressed through their dissertation. Of the 7 students who submitted their work under the heading Chapter 1 and the subsequent heading Chapter 2, 
the similarity scores for 6 of the students actually increased! Some of these increased scores were negligible (e.g. Student F from $2 \%$ to $3 \%$ ), while other increases were either significant (Student C: $10 \%$ to $16 \%$ ) or both significant and alarming (Student E: $3 \%$ to $31 \%$ ). Even where the decrease in score occurred it was still a significant figure (Student A: $22 \%$ to $17 \%$ ). However, if we keep an eye of these very same students when they submit under Chapter 3, they all reduce their similarity scores (bar one who did not submit and another who gained the same low score). Of those students who submitted for the first time under Chapter 2 (7 students) and then submitted under Chapter 3, 4 of the students decreased their scores when submitting under Chapter 3 (all quite impressively) while one retained the same high score (Student L: $20 \%$ to 20\%) and two others increased their similarity scores, one marginally (Student S: 3\% to 4\%), the other significantly (Student R: $5 \%$ to $23 \%$ ). It may be that the latter group of students (who started late in using Turnitin) have learned from their peers on how to lower similarity scores. If the "late" group follow the trend set by the earlier group of students then it is in the third iteration of submission where they will collectively lower their similarity scores. From Table 3 it can be seen that of the 49 students on the dissertation module only 20 students, at one time or another, submitted parts of their dissertation into Turnitin.

Table 3. Study of Similarity Scores over Time

\begin{tabular}{|l|l|l|l|}
\hline & "Chapter 1" & "Chapter 2" & "Chapter 3" \\
\hline Student A & $22 \%$ & $17 \%(-)$ & $7 \%(-)$ \\
\hline Student B & $16 \%$ & & \\
\hline Student C & $10 \%$ & $16 \%(+)$ & $9 \%(-)$ \\
\hline Student D & $9 \%$ & & \\
\hline Student E & $3 \%$ & $31 \%(+)$ & \\
\hline Student F & $2 \%$ & $3 \%(+)$ & $0 \%(-)$ \\
\hline Student G & $2 \%$ & & \\
\hline Student H & $1 \%$ & $4 \%(+)$ & $0 \%(-)$ \\
\hline Student I & $1 \%$ & & \\
\hline Student J & $0 \%$ & $3 \%(+)$ & $3 \%(=)$ \\
\hline Student K & $0 \%$ & $17 \%(+)$ & $8 \%(-)$ \\
\hline Student L & - & $20 \%$ & $20 \%(=)$ \\
\hline Student M & - & $13 \%$ & \\
\hline Student N & - & $11 \%$ & \\
\hline Student O & - & $11 \%$ & $2 \%(-)$ \\
\hline Student P & - & $10 \%$ & $3 \%(-)$ \\
\hline Student Q & - & $7 \%$ & $1 \%(-)$ \\
\hline Student R & - & $5 \%$ & $23 \%(+)$ \\
\hline Student S & - & $3 \%$ & $4 \%(+)$ \\
\hline Student T & - & - & $3 \%$ \\
\hline
\end{tabular}

\section{Phase 2 of Study: Final Submissions}

Students submitted their final dissertation in April 2009 and the following data was gathered and analysed around this time (Figure 4). In total there were 244 submissions across all Turnitin 'assignments' (5 dissertation chapters; final draft plus the final dissertation) by 49 students This averaged at 5 submissions per student with the maximum number of 14 submissions by any one student. Forty nine students submitted their final dissertation to Turnitin but for 6 students this was their one and only submission as they 
had not used Turnitin to test their chapters during the writing process or their draft dissertation. This was despite repeated reminders by the module leader.

Figure 4. Overall Frequency of submissions

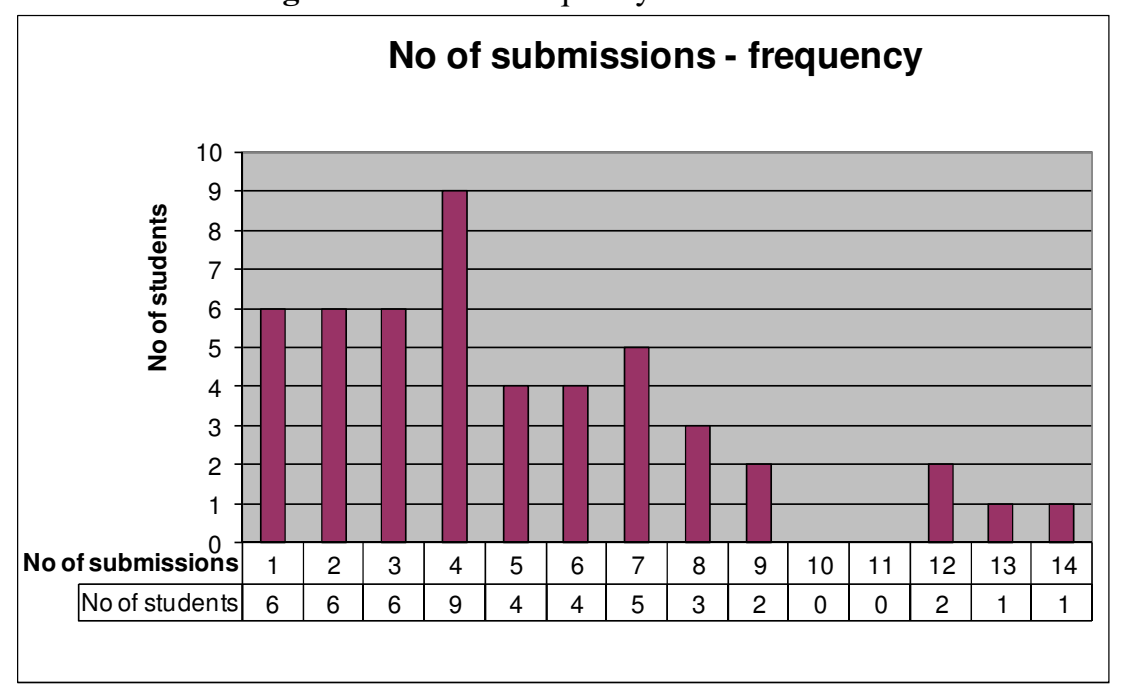

Table 4 demonstrates that, with the exception of the compulsory submission of the final dissertation, most activity involved chapters 1-3, with the highest number of submissions for the literature review and conclusions having the lowest submission rate. These figures are not unexpected as students tend to have most difficulty writing their literature review as this involves the most 'academic' writing using referencing and paraphrasing, while the conclusions tend to be very applied to their own research and involve very little referencing. Surprisingly only 27 of the total 49 students took advantage of the opportunity to submit a draft version of their dissertation.

Table 4 Submissions per chapter

\begin{tabular}{|l|l|l|l|}
\hline Chapter & Approximate Chapter Content & $\begin{array}{l}\text { No of } \\
\text { submissions }\end{array}$ & No of students \\
\hline 1 & Introduction & 49 & 35 \\
\hline 2 & Literature Review & 54 & 40 \\
\hline 3 & Methodology & 41 & 37 \\
\hline 4 & Findings \& Discussion & 25 & 21 \\
\hline 5 & Conclusions \& recommendations & 19 & 18 \\
\hline Draft & Complete draft of dissertation & 34 & 27 \\
\hline Final & Final version of dissertation & 49 & 49 \\
\hline
\end{tabular}

Considering the total number of students who submitted per chapter it is evident that many students only submitted each of their dissertation chapters through Turnitin at most once i.e. they used Turnitin to check their work for originality but did not use it for redrafting and resubmission of writing of individual chapters. Of the students who did resubmit chapters: in chapter 1 (the Introduction), the work of 5 students improved while 4 students' work did not; in chapter 2 (Literature Review), the work of 6 students improved; in chapter 3 (Methodology) the work of 3 students; in chapter 4 (Findings) the work of 1 student improved; and in chapter 5 (conclusions) no students' work improved. 
Figure 5: Number of Turnitin submissions v Final Mark

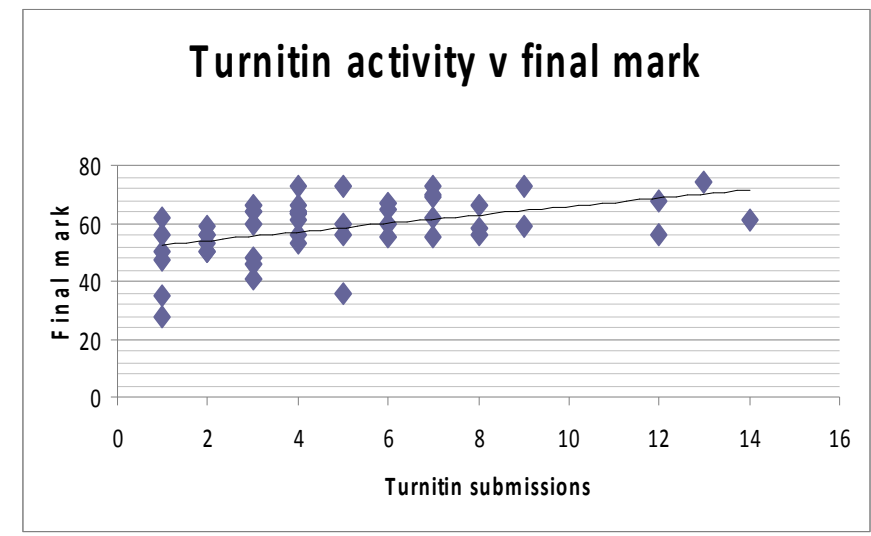

The above scatter diagram shows the final mark that students received for their dissertation compared to their Turnitin activity i.e. the amount of times they submitted work through Turnitin. The correlation score $(\mathrm{r}=0.47)$ confirms that there is possibly a weak correlation between the 2 sets of data, but nothing significant. Using Turnitin appeared to have little effect on the final outcome of the dissertation mark.

When the final submission date was analysed against Turnitin scores it was evident that 4 of 5 highest scores achieved were from students who had submitted late (extensions were granted). Such extensions were for personal circumstances such as illness or problems at home and their Turnitin score is an indication that these students possibly require further support. However, overall submission date against Turnitin score has a weak correlation of $r=0.51$. A further interesting finding that was highlighted by Turnitin within the late submissions was collusion between 2 students. As dissertations are marked by a number of different supervisors, it is unlikely that this transgression would have been spotted otherwise.

One objective of this project was to improve students' academic writing and therefore improve overall results achieved for the dissertation. The following table shows the results achieved for the 6 year period $2003-2009$ together with the mean and standard deviation for each year:

Table 5: Dissertation Results 2003-2009

\begin{tabular}{|l|l|l|l|l|l|l|}
\hline \multirow{2}{*}{$\begin{array}{l}\text { Final } \\
\text { mark }\end{array}$} & \multicolumn{7}{|c|}{ Number of students } \\
\cline { 2 - 7 } & $\mathbf{2 0 0 3 - 4}$ & $\mathbf{2 0 0 4 - 5}$ & $\mathbf{2 0 0 5 - 6}$ & $\mathbf{2 0 0 6 - 7}$ & $\mathbf{2 0 0 7 - 8}$ & $\mathbf{2 0 0 8 - 9}$ \\
\hline $70+$ & 6 & 6 & 7 & 7 & 4 & $\mathbf{5}$ \\
\hline $60-69$ & 29 & 27 & 17 & 17 & 12 & $\mathbf{2 0}$ \\
\hline $50-59$ & 42 & 24 & 19 & 19 & 21 & $\mathbf{1 7}$ \\
\hline $40-49$ & 10 & 4 & 7 & 7 & 4 & 4 \\
\hline $30-39$ & 0 & 0 & 0 & 0 & 0 & $\mathbf{2}$ \\
\hline$<30$ & 0 & 0 & 0 & 0 & 0 & $\mathbf{1}$ \\
\hline Total & 87 & 61 & 50 & 50 & 41 & $\mathbf{4 9}$ \\
\hline Mean & 54.7 & 58.5 & 59.1 & 56.8 & 57.9 & $\mathbf{5 8 . 6}$ \\
\hline S D & 14.5 & 8.1 & 9.3 & 11.5 & 7.6 & $\mathbf{1 0 . 3}$ \\
\hline
\end{tabular}

The figures demonstrate that overall results have not improved significantly by using Turnitin this way. However further analysis is still required on the number of 
instances of plagiarism and the overall improvement in academic writing, independent of final marks achieved.

\section{Conclusion}

This paper discussed a two-part pilot study in using Turnitin as a way to educate students on plagiarism, improve their referencing skills and, in the end, cut down acts of plagiarism. This project produced a mix bag of results, providing pointers for future action:

- $\quad$ Of the 49 students who completed the module, only 42 students made use of the Turnitin facility to check each chapter as they completed it (only in the submission of the final dissertation is the use of Turnitin compulsory) and redrafting and resubmission of work was not carried out by the majority.

- Activity in the form of submissions to Turnitin was slow to start, with relatively few submissions by the beginning of March (the dissertation submission date was at end of April). This is probably indicative of the way that students work in general with a concentrated effort as the deadline approaches. Obviously students' time management could be improved and the module team will again endeavor to address this.

- Despite the use of Turnitin, supervisors reported that there was still incorrect referencing and minor plagiarism detected in final work in the form of direct copying of text and patchwork plagiarism. Where similarities between the student's work and the source text were highlighted, students did not seem to spend any time trying to paraphrase the author's work: they either copied it directly or replaced the odd word with (what they thought was) a synonym. This highlights that a wider effort is required to combat plagiarism which may include further education on what constitutes plagiarism.

- Also, as students progressed through their dissertation, and entered more chapters of their dissertation to Turnitin, their similarity scores decreased. This suggests that either students were learning how to get around Turnitin or were genuinely learning from earlier mistakes.

- One had to be cautious about viewing the similarity scores as an indication of the level of assistance that a student might need. For example, where some students scored low in the similarity match, they still required help in terms of how they tackled the dissertation; similarly, some students who had relatively high similarity scores, had actually written a good piece of work.

- Turnitin reports were useful for supervision staff as they could be used to discuss students' writing styles as well as the sources referenced. The slow rate of student submissions also alerted supervisors of students' poor time management. However, not all supervisors used Turnitin on a regular basis and it was discovered that 6 (out of 21) supervisors did not access it at all. It was left to the module leader to overview the submissions and highlight poor writing style to supervisors and to check all final submissions for any instances of plagiarism or collusion.

The lack of active participation by dissertation supervisors (in the exploitation of Turnitin's facilities) may be a significant factor in influencing student use of Turnitin. If students do not receive feedback from their supervisors with respect to their Turnitin submissions then it is likely that students will switch off from using Turnitin as a learning tool. Further effort is therefore needed not only to encourage students to submit work to Turnitin but also to encourage supervising staff to open up a dialogue with students and, together, make best use of Turnitin's facilities.

\section{References}

Biggam, J., 2007. Give Credit where Credit is Due: e-Plagiarism and Universities. Proceedings of International Association for Technology, Education and Development (INTED). Valencia, Spain.

Biggam, J., 2008. Succeeding With Your Masters Dissertation - A Step-By-Step Guide. Open University Press: London. 
Davis, M., 2007. Creating Learning and Unlearning Opportunities from Turnitin in the Process of Academic Writing. Proceedings of Designing for Learning Conference. London, UK, pp. 47-51.

Garbarino, E. and Strahilevitz, M. 2004. Gender Differences in the Perceived Risk of Buying Online and the Effects of Receiving a Site Recommendation, Journal of Business Research, Vol. 54, pp. 768-775.

Hayes, N. and Introna, L. D., 2005. Cultural Values, Plagiarism, and Fairness: When Plagiarism gets in the way of Learning. Ethics and Behaviour, Vol. 15, No. 3, pp. 213-231.

Kantor, A., 2006. Technological Arms Race over Plagiarism in Schools is Worth Watching. USA Today. July 16. Available from: http://www.usatoday.com.

Marshall, S. and Garry, M., 2006. NESB and ESB Students' Attitudes and Perceptions of Plagiarism. International Journal of Educational Integrity, Vol. 2, No. 1, pp. 26-37.

Park, C., 2003. In other (people's) words: Plagiarism by University Students - Literature and Lessons. Assessment and Evaluation in Higher Education, Vol. 28, No. 5, pp. 271.

Peacock, S. et al., 2006. Pickup a Plagiarism Practice? A Holistic Approach to Deploying Turnitinuk as a Sustainable Driver in Altering Institutional Plagiarism Practice. Proceedings of JISC International Plagiarism Conference. Newcastle, UK.

Regan, J., 2008. Curing the Cold but Killing the Patient? Turnitin.com, Online Paper Mills, and the Outsourcing of Academic Work. Plagiary: Cross-Disciplinary Studies in Plagiarism, Fabrication and Falsification, Vol. 3, No. 2, pp 1-11. 